\title{
Awake Fiberoptic Assisted Nasotracheal Intubation in Oral Malignancies - A Comparison between Airway Blocks and LA Spray - A Randomized, Interventional Crossover Trial
}

\author{
Gajanan Namdeorao Chavan¹, Akanksha Saurabh Aggarwal2 ${ }^{2}$ Parwez Khan $^{3}$, Ritu Mridul Sahi ${ }^{4}$ \\ ${ }^{1}$ Department of Emergency Medicine, Jawaharlal Nehru Medical College, Sawangi Meghe, \\ Wardha, Maharashtra, India. ${ }^{2}$ Department of Anaesthesia, Chirayu Medical College, Bhopal, \\ Madhya Pradesh, India. ${ }^{3}$ Department of Jawaharlal Cancer Hospital, Bhopal, Madhya \\ Pradesh, India. ${ }^{4}$ Department of Anaesthesia, Chirayu Medical College, Bhopal, Madhya \\ Pradesh, India.
}

\section{ABSTRACT}

\section{BACKGROUND}

Awake fiberoptic assisted nasal intubation is the gold standard for securing airway in cases of oral malignancy posted for radical surgeries. Different techniques such as airway blocks, LA gargles, spray, nebulization along with light sedation are in practice. We wanted to evaluate the efficacy of airway blocks over airway spray for intubation conditions, time taken to intubation, patient comfort and complications.

\section{METHODS}

This randomized, interventional and crossover study was conducted at Chirayu Medical College and Hospital. A total of 60 patients of ASA grade I-II with Mallampati score $3 \& 4$ undergoing wide local excision and neck dissection were selected after fulfilling of the selection criterion and were divided into two groups, Airway Block $(A B, n-30)$ and Airway Spray group (AS, n-30). AB group received bilateral superior and transtracheal recurrent laryngeal nerve blocks and group AS local anaesthetic spray through the working channel of the fiberoptic scope. Haemodynamics, time taken for intubation, intubating conditions, patients' comfort, and complications if any were noted. All data was tabulated and analysed using software SPSS 17.0.

\section{RESULTS}

Mean total time taken for intubation in seconds was less. Intubating conditions were optimal in $90 \%$ cases. 5-point comfort during and 3-point score immediately after intubation were excellent in $\mathrm{AB}$ compared AS group. Haemodynamically both the groups were comparable.

\section{CONCLUSIONS}

Combined block of the superior and recurrent laryngeal nerves provides optimal conditions to facilitate a successful fibreoptic assisted awake nasotracheal intubation in anticipated difficult airway.

\section{KEY WORDS}

Airway, Fibreoptic Assisted Intubation, Airway Blocks, Superior Laryngeal Nerve Blocks, Local Anaesthetic
Corresponding Author:

Dr. Gajanan Namdeorao. Chavan, GP-200, Lake Pearl Spring Society, Abbas Nagar, Near Gandhi Nagar, Opposite Woods in Restraraunt, Bhopal, Madhya Pradesh, India. E-mail: gcgcny@gmail.com

DOI: $10.14260 /$ jemds/2020/526

How to Cite This Article:

Chavan GN, Aggarwal AS, Khan P, et al. Awake fibreoptic assisted nasotracheal intubation in oral malignancies - a comparison between airway blocks and LA spray - a randomized, interventional crossover trial. J Evolution Med Dent Sci 2020;9(34):2417-2421, DOI: $10.14260 /$ jemds $/ 2020 / 526$

Submission 11-04-2020,

Peer Review 10-07-2020,

Acceptance 17-07-2020,

Published 24-08-2020.

Copyright (C) 2020 JEMDS. This is an open access article distributed under Creative Commons Attribution License [Attribution 4.0 International (CC BY 4.0)] 


\section{BACKGROUND}

Oral malignancies are common in India due to tobacco and betel nut chewing. ${ }^{(1,2)}$ Radical neck dissection along with reconstruction is the first choice of treatment for oral cancer.(1) These patients usually come in late stage and poses a common concerns to Anaesthesiologist in the terms of difficult airway firstly because of tumour itself, restricted mouth opening and finally decreased inter incisor gap. Some patients may have received radiotherapy or chemotherapy as the primary modality of therapy for oral cancer and are likely to have limited neck movements and extension difficulties with restricted mouth opening.(3)

Establishing a patent airway for General anaesthesia in these patients is always challenging for anaesthesiologists and risky to the patients. $(4,5)$ The Competent authorities and many esteemed authors recommend Awake fibreoptic assisted intubation(6) where difficult intubation is anticipated, which can lead to the life-threatening "can't intubate, can't ventilate scenario." Nasotracheal intubation provides the oncosurgeon a optimal operating conditions for mouth, pharynx, larynx and neck surgeries. ${ }^{(7)}$

An idea of being awake and nasotracheal manipulations could be highly freighting to the patient, sufficient time and effort must be spent to prepare these patients both psychologically and pharmacologically. Treating anaesthesiologist should initiate psychological preparation by explaining procedure in patients mother tongue. $(8,9)$ Judicious use of Sedative and opioids should be practiced to achieve patient comfort without compromising airway patency. Once the patient perceives the anaesthesiologist to be empathetic and understanding, the major portion of the battle is won.(10)

Several authors have reported that FOI can be achieved with considerable haemodynamic stability(11-13) under local anaesthetic when combined with sedation. Anxiety may lead to undesirable stimulation of patients sympathetic and parasympathetic systems which may lead to elevation of heart rate and blood pressure, along with troublesome excessive secretions and enhanced protective reflexes, making intubation near impossible. Knowledge of innervations and anatomy of the airway to be blocked are essential to achieve the desired effects. ${ }^{(9,14)}$ Several efficient topical and regional techniques are being used to subdue these unwanted reflexes by reducing sensations at specific regions that have to be encountered during intubation.(15) Topical anaesthesia by Local anaesthetic can be achieved by different ways such as, spray, nebulisation, atomization, gargles and topicalization.(16) However, the effect could be spotty and if the dose exceeds the recommended range may lead to systemic toxicity in this already compromised patients. In heavily sedated patients with unstable cervical fracture, insufficient topicalization led to laryngospasm with total upper airway obstruction as a result of fiberoptic pharyngeal mucosa stimulation.(16)

Airway blocks, on the other hand, are considered technically more difficult to perform and generally carry a higher risk of complications including bleeding, nerve damage, and intravascular injection. However, in experienced hands, they can be useful as they provide excellent anaesthesia and intubating conditions. For complete upper airway anaesthesia, a bilateral glossopharyngeal nerve (GPN) block, bilateral superior laryngeal nerve (SLN) block and trans laryngeal injection are required. Intraoral glossopharyngeal nerve block is safe and easy to perform, but associated with long lasting discomfort. Bilateral extraoral peristyloid approach should be discouraged since inadvertent blocks of the closely adjacent vagus nerves cannot be prevented.(17)

Insufficient availability of the scientific research provokes us to design this randomized, interventional study to assess and compare, the efficacy of easy to perform airway blocks with conventional spray technique to achieve upper airway anaesthesia for awake FOB guided nasotracheal intubation.

\section{METHODS}

After approval of the protocol by the Institutional Research Committee, this interventional, crossover study was conducted at Oncosurgery OT of Chirayu medical college and Hospital, Bhopal, MP during April 2017-April 2018. The study was registered with Clinical Trail registry India (CTRI/2017/05/008571 [Registered on: 16/05/2017] Trial Registered Retrospectively.

In present study the sample size of total 60 willing and cooperative adults of age 18-80 years of ASA (American Society of Anaesthesiologist) status I-II having intraoral malignancies posted for wide local excision and neck dissection were recruited for the study by taking in consideration of Level of Significance. Non-Willing, Uncooperative, allergic to Local Anaesthetic, Haematological disorders, psychiatric ailments and patients with malignancies involving posterior third of tongue, tonsils or Larynx were excluded from the study.

A through preoperative evaluation including a complete airway evaluation (mouth opening, Mallampati grade, TM distance and neck movements) was performed. Standard fasting guidelines and anti-aspiration prophylaxis with Inj. Ranitidine $50 \mathrm{mg}$ were prescribed. The patients were explained in detail about the awake FOB (Fiberoptic) guided intubation in the pre-anaesthetic evaluation in their mother tongue and informed consent were obtained.

All the study subjects were given Inj. Glycopyrrolate $0.2 \mathrm{mg}$ IV in receiving area before shifting to OT through newly established iv line with 18G canula. Inside the OT, standard monitoring including 5 lead Electrocardiogram (ECG), noninvasive blood pressure pulse oximeter and $\mathrm{EtCO}_{2}$ by placing sensor inside the oxygen mask were attached to the patients. Inj. Midazolam $1 \mathrm{mg}$ and Inj. Fentanyl $50 \mathrm{mcg}$ were given IV after recording the base line vitals.

The patients were randomly allocated into two groups Airway block (AB) and Airway Spray as you go (AS). Randomization was done using computer generated closed envelope method. All the patients nostrils were instilled with Xylometazoline 1\% (2-3) nasal drops and then gauge soaked in $4 \%(5 \mathrm{~mL})$ was placed in the nostrils for 5 minutes, preferred nostril for FOB intubation was progressively dilated with silicone nasopharyngeal airway starting 6.5 up to $7.5 \mathrm{~mm}$ smeared with $2 \%$ lignocaine jelly.

Group AB (n- 30) were given bilateral Superior Laryngeal Nerve block with $2 \%$ plain Xylocaine $(2 \mathrm{~mL}$ each) and transtracheal instillation (recurrent laryngeal nerve) of $2 \%$ Xylocaine $(2 \mathrm{~mL})$. Six minutes wait was done. Hoarseness of voice was taken as adequate effect. Group AS (n-30) received $2 \mathrm{~mL}$ Local Anaesthetic spray at nasopharynx, oropharynx, 
larynx and post vocal cords ( fully adducted) under vision in $360^{\circ}$ by $18 \mathrm{G}$ multi orificed epidural catheter inserted through the working side channel of FOB (Olympus LF-DP, Tokyo, Japan) with $10 \mathrm{~mL}$ of syringe filled of $2 \%$ Xylocaine at 30 seconds interval after satisfactory spray the FOB was withdrawn.

The maximum allowable LA dose was up to $5 \mathrm{mg} / \mathrm{Kg}$ in both the groups. FOB was loaded with flexometallic ETT 7.5 $\mathrm{mm}$ for female and $8.0 \mathrm{~mm}$ for male patients. Airway anaesthesia was performed by experienced anaesthesiologists in managing difficult airways. A dedicated anaesthesia technician recorded all the events with stopwatch during the procedure. Time taken for intubation was from nostril up to 2 $\mathrm{cm}$ below vocal cords in both the groups. Patients were assessed for Intubation score during the passage of FOB and patients comfort score (Table-1), and any complications during the procedure were noted. Any sign of LAST such as ECG changes, neurological symptoms were also looked for.

Oxygenation was done continuously by venti mask with 4 liter flow, mask was modified by cutting a hole at the top for FOB insertion. After passage of ETT into trachea and carina under vision General Anaesthesia was administered with Propofol $2 \mathrm{~mL} / \mathrm{kg}$ and Rocuronium $0.6 \mathrm{~mL} / \mathrm{Kg}$ and connected to the ventilator. haemodynamic monitoring was concluded after 4 minutes post intubation.

\section{Statistical Analysis}

All data was tabulated and analysed using software SPSS 17.0. All continuous parametric data were compared using the unpaired Students t-Test and non-parametric data such as intubation grade and patients comfort score were compared using Chi-square test. Statistical significant value was considered if $\mathrm{p}<0.05$, and if $\mathrm{p}<0.001$ as highly significant. Results were analysed and compared with previous studies. Power of the study was calculated to be above $90 \%$.

\section{RESULTS}

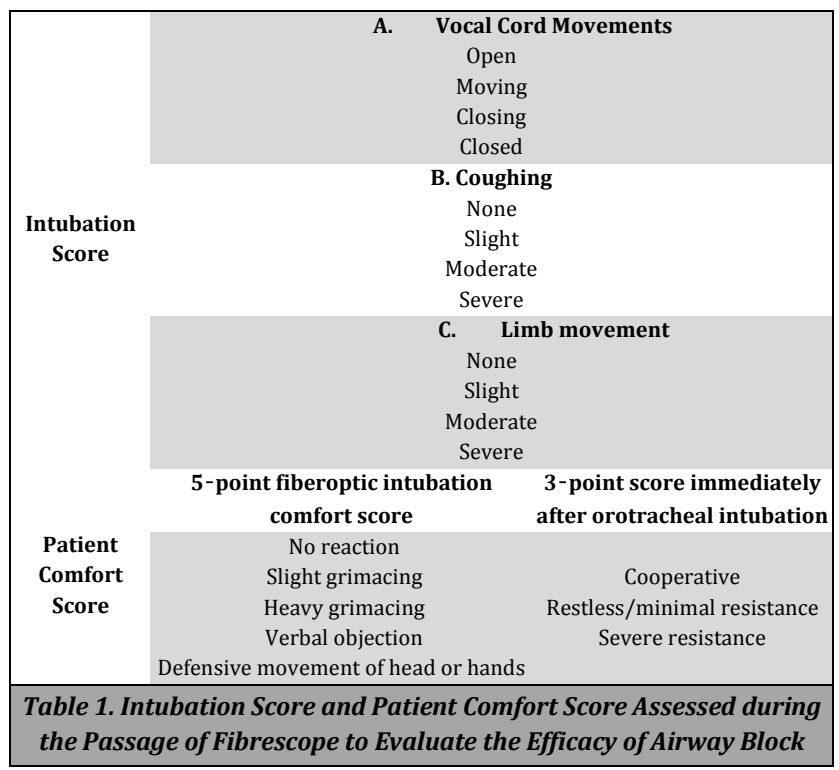

\begin{tabular}{|c|c|c|c|c|}
\hline Age (Mean) & \multicolumn{2}{|c|}{$\begin{array}{c}\text { Airway Spray (AS) } \\
47.03 \pm 10.4\end{array}$} & \multicolumn{2}{|c|}{$\begin{array}{c}\text { Airway Block (AB) } \\
46.83 \pm 8.0\end{array}$} \\
\hline \multirow{2}{*}{ Sex } & Male & Female & Male & Female \\
\hline & 23 & 7 & 25 & 5 \\
\hline & \multicolumn{2}{|c|}{ AS } & \multicolumn{2}{|l|}{ AB } \\
\hline \multirow{2}{*}{ Mallampati Score } & III & IV & III & IV \\
\hline & 19 & 11 & 15 & 15 \\
\hline Mouth Opening Mean & \multicolumn{2}{|c|}{ AS } & $\begin{array}{l}15 \\
\mathrm{AB}\end{array}$ & \\
\hline$+{ }_{-} \mathrm{SD}$ & \multicolumn{2}{|c|}{$1.13+\_0.35$} & $1.03+-0.46$ & \\
\hline Thyromental Distance & \multicolumn{2}{|c|}{ AS } & $\mathrm{AB}$ & \\
\hline Mean \pm SD & \multicolumn{2}{|c|}{$3.87+0.63$} & $3.99+\_0.60$ & \\
\hline \multirow{2}{*}{ Neck Movements } & Normal & Decrease & \multicolumn{2}{|l|}{ Normal Decrease } \\
\hline & 27 & 3 & 30 & \\
\hline Complications & \multicolumn{2}{|c|}{ AS } & $\mathrm{AB}$ & \\
\hline Bradycardia & \multicolumn{2}{|c|}{2} & 0 & \\
\hline Tachycardia & \multicolumn{2}{|c|}{10} & 2 & \\
\hline Hypertension & \multicolumn{2}{|c|}{ 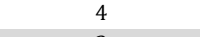 } & 2 & \\
\hline Laryngospasm & & 0 & \\
\hline $\begin{array}{l}\text { Time taken for Intubation in } \\
\text { Seconds }\end{array}$ & \multicolumn{2}{|c|}{ AS } & $\mathrm{AB}$ & \\
\hline Nostril- Nasopharynx & \multicolumn{2}{|c|}{$35.59 \pm 16.65$} & \multicolumn{2}{|l|}{$39.5 \pm 20.46$} \\
\hline Nasopharynx - Trachea & \multicolumn{2}{|c|}{$229.31 \pm 111.630$} & \multicolumn{2}{|l|}{$160.96 \pm 142.48$} \\
\hline Total time taken for Intubation & \multicolumn{2}{|c|}{$266.62 \pm 115.86$} & \multicolumn{2}{|l|}{$200 \pm 146.35$} \\
\hline \multicolumn{5}{|c|}{$\begin{array}{c}\text { Table 2. Demographic Data, Mallampati Score, Mouth Opening, } \\
\text { Thyromental Distance, Neck Movements, Complications and Time } \\
\text { Taken for Intubation }\end{array}$} \\
\hline
\end{tabular}

\begin{tabular}{|c|c|c|c|}
\hline Intubating Condi & tions & $\overline{A S}$ & $\overline{\mathrm{AB}}$ \\
\hline Optimal & & 11 & 27 \\
\hline Suboptimal & & 16 & 3 \\
\hline Difficult & & 1 & 0 \\
\hline Failed & & 2 & 0 \\
\hline \multicolumn{4}{|c|}{ Optimal vs other groups- Chi square value 7.9 , $p$ value $<0.04$} \\
\hline \multicolumn{2}{|c|}{ 3-point comfort score } & AS & $\mathrm{AB}$ \\
\hline \multirow{3}{*}{ Vocal cord movements } & Open & 3 & 23 \\
\hline & Moving & 25 & 6 \\
\hline & Closed & 2 & 1 \\
\hline \multirow{4}{*}{ Coughing } & Slight & 14 & 7 \\
\hline & None & 10 & 23 \\
\hline & Moderate & 3 & 0 \\
\hline & Severe & 3 & 0 \\
\hline \multirow{3}{*}{ Limb Movement } & Slight & 9 & 7 \\
\hline & Moderate & 14 & 2 \\
\hline & None & 7 & 21 \\
\hline \multicolumn{4}{|c|}{$\begin{array}{l}\text { In vocal cord open vs other }- \text { Chi square value } 27.15 \quad \text { p value }<0.001 \\
\text { In coughing none vs other groups- Chi square value } 11.38 \text { p value }<0.01 \\
\text { In Limb movement None vs others- Chi square value } 13.12 \text { p value }<0.001\end{array}$} \\
\hline \multicolumn{4}{|c|}{$\begin{array}{ccc}\text { In Limb movement None vs others- Chi square value } 13.12 \mathrm{p} \text { value }<0.001 \\
\mathbf{5} \text { Points } & \text { AS } & \text { AB }\end{array}$} \\
\hline No Reaction & \multicolumn{2}{|c|}{2} & 17 \\
\hline Slight Grimacing & \multicolumn{2}{|c|}{23} & 11 \\
\hline Heavy Grimacing & \multicolumn{2}{|c|}{2} & 2 \\
\hline Verbal Objection & \multicolumn{2}{|c|}{1} & 0 \\
\hline $\begin{array}{l}\text { Defensive Head \& Hand } \\
\text { Movements }\end{array}$ & \multicolumn{2}{|c|}{2} & 0 \\
\hline \multicolumn{4}{|c|}{ No reaction vs others - Chi square value 17.33 p value $<0.001$} \\
\hline \multicolumn{4}{|c|}{$\begin{array}{l}\text { Table 3. Grades of Intubating Conditions, } 3 \text { and } 5 \text { Point Intubation } \\
\text { Score Assessed During FOB Passage }\end{array}$} \\
\hline
\end{tabular}

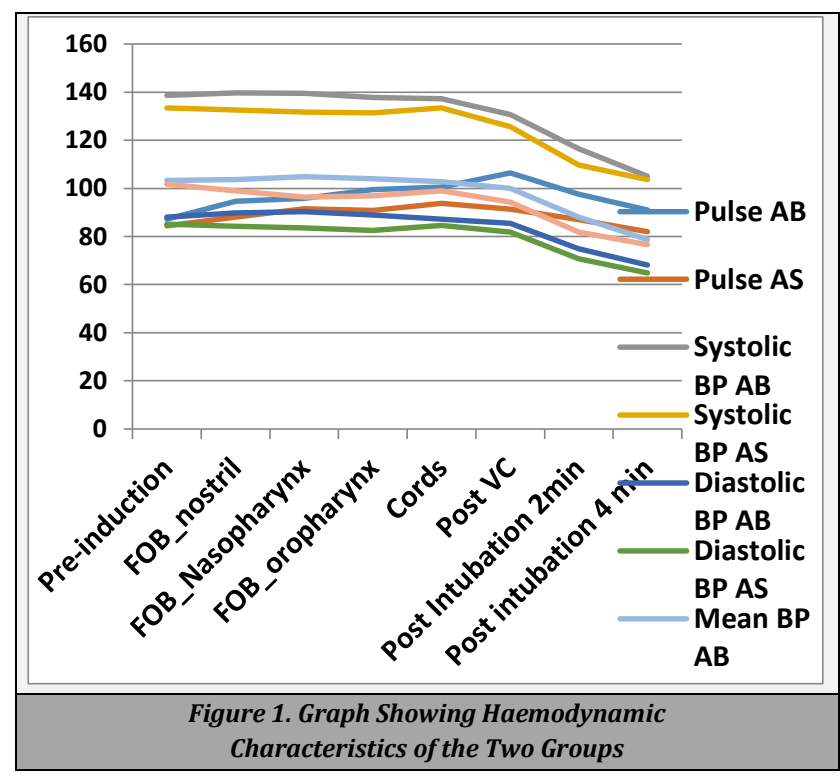




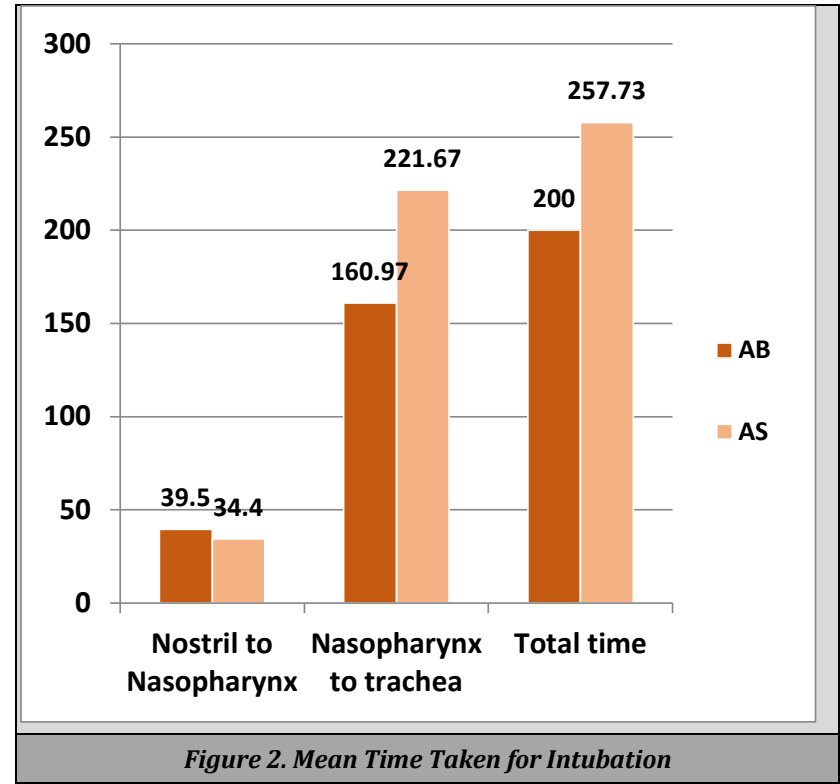

The demographic data (T2) was comparable in two groups. There was no significant difference in HR and BP in groups (Figure-1). However, there was slight drop in $\mathrm{SpO}_{2}$ up to $95 \%$ in group AS during FOB at cords and continued to post cord position (Figure. 2). All patients remained awake and cooperative, but, 2 patients in AS group developed Laryngospasm and to be intubated with administration of GA (T2). The total time taken for intubation was 200 (156.48261.59) sec in AB group which was significantly less than AS groups 257.73 (212.97-304.43) sec. (Table 2 and Figure 2). Intubation score was optimal in $90 \%$ of cases in $\mathrm{AB}$ group as compared to $36 \%$ in AS group (Table 3). 3 Point patient comfort during FOB passage through vocal cords was statistically highly significant in $\mathrm{AB}$ as compared to AS group with $\mathrm{p}<0.01$ (Table 3), similarly, 5-point score in no reaction was excellent in $\mathrm{AB}$ group (Table 3).

\section{DISCUSSION}

Awake FOB assisted tracheal intubation was practiced first by Murphy in 1967 and is being extensively authenticated by different authors in management of difficult intubation.(18-20) However there are very limited studies in search engine like PubMed over the studies like we decided to conduct.

Patients with oral malignancy always falls in the category of anticipated difficult airway and intubation due to various reasons and FOB assisted nasotracheal intubation is safest method to achieve it.(21) If GA is given to these patients the difficult airway algorithm which includes call for help may not be applicable as time won't be there.(22)

An awake FOB intubation allows the patient to maintain the tone of airway hence provides a degree of safety margin which is lost if the patient is given GA. $(4,23)$. Awake FOB intubation is challenging to anaesthesiologist and frightening to the patient, hence, proper preoperative empathic counseling is extremely vital to succeed. Judicious use of antisialagogues, anxiolytics and analgesics is also mandatory. $(8,9)$ Different conventional modalities to anaesthetize the passage to negotiate the FBO such as, atomization, nebulisation gargles, spray and lozenges are in use. These conventional modalities do not always provide satisfactory results and are associated with drawbacks like spotty coverage, LAST and even loss of the airway, along with heightened sensitivity which can lead to complication like Laryngospasm.

In our study, the mean time taken for intubation was significantly less in AB to AS group, our results contradicts with study done by Reasoner et al.(24) This was probably due to supplementation RLN block, which might have improved the anaesthesia. We have similar trend in mean time taken for intubation to the study conducted by Gupta(25) and Veena et al.(26) Kundra et al(27) compared nebulisation of $4 \%$ lignocaine with airway blocks( RLN, SLN) and quoted higher stress, grimace scores and haemodynamic fluctuations in nebulisation group during FOB passage which corresponds to present study. Gupta et al(25), Ovassapian et al,(11) Graham et al(28) and Trivedi et al(29) studies have similar outcome as of our study in the terms of intubation score and patients comfort in their nerve block groups. Complications observed in present study were also mentioned in different protocols but statistical significance could not be established.

Bilateral SLN and transtracheal RLN block, adequate mental and pharmacological preparation of upper airway and empathetic attitude towards patients aids in achieving FOB assisted intubation in awake patients as compared to only spray technique.

Our study have limitation of minimal bias as it is not a blind study and secondly our institution is not equipped with facility to measure serum lignocaine levels.

\section{CONCLUSIONS}

Awake FOB assisted nasotracheal intubation done with combined airway nerve blockade provides optimal intubating conditions and achieves excellent patient comfort with nonsignificant haemodynamic effects.

Financial or Other Competing Interests: None.

\section{REFERENCES}

[1] Shah JP, Gil Z. Current concepts in management of oral cancer--surgery. Oral Oncol 2009;45(4-5):394-401.

[2] Sankaranarayanan R. Oral cancer in India: an epidemiological and clinical review. Oral Surg Oral Med Oral Pathol 1990;69(3):325-30.

[3] Hancock PJ, Epstein JB, Sadler GR. Oral and dental management related to radiation therapy for head and neck cancer. J Can Dent Assoc 2003;69(9):585-90.

[4] Benumof JL. Management of the difficult adult airway. With special emphasis on awake tracheal intubation. Anaesthesiology 1991;75(6):1087-110.

[5] Barash PG, Cullen BF, Stoelting RK. Clinical anaesthesia. $5^{\text {th }}$ edn. Philadelphia: Lippincott Williams \& Wilkins 2006:621-30. 
[6] Wilson ME, Spiegelhalter D, Robertson JA, et al. Predicting difficult intubation. Br J Anaesth 1988;61(2):211-6.

[7] Hall CEJ, Shutt LE. Nasotracheal intubation for head and neck surgery. Anaesthesia 2003;58(3):249-56.

[8] Ramkumar V. Preparation of the patient and the airway for awake intubation. Indian J Anaesthesia 2011;55(5):442-7.

[9] Pani N, Rath SK. Regional \& topical anaesthesia of upper airways. Indian J Anaesth 2009;53(6):641-8.

[10] Farsad P, Galliguez P, Chamberlin R, et al. Teaching interviewing skills to pediatric house officers. Pediatrics 1978;61(3):384-8.

[11] Ovassapian A, Yelich SJ, Dykes MH, et al. Blood pressure and heart rate changes during awake fibreoptic nasotracheal intubation. Anaesth Analg 1983;62(10):951-4.

[12] Sutherland AD, Williams RT. Cardiovascular responses and lidocaine absorption in fiberoptic-assisted awake intubation. Anaesth Analg 1986;65(4):389-91.

[13] Hawkyard SJ, Morrison A, Doyle LA, et al. Attenuating the hypertensive response to laryngoscopy and endotracheal intubation using awake fibreoptic intubation. Acta Anaesthesiol Scan 1992;36(1):1-4.

[14] Simmons ST, Schleich AR. Airway regional anaesthesia for awake fiberoptic intubation. Reg Anaesth Pain Med 2002;27(2):180-92.

[15] Walsh ME, Shorten GD. Preparing to perform an awake fiberoptic intubation. Yale J Biol Med 1998;17(6):537-49.

[16] McGuire G, el-Beheiry H. Complete upper airway obstruction during awake fiberoptic intubation in patients with unstable cervical spine fractures. Can J Anaesth 1999;46(2):176-8.

[17] Pintarič TS. Upper airway blocks for awake difficult airway management. Acta Clin Croat 2016;55(Suppl 1):85-9.

[18] Edens ET, Sia RL. Flexible fiberoptic endoscopy in difficult intubations. Ann Otol Rhinol Laryngol 1981;90(4 Pt 1):307-9.
[19] Monrigal JP, Granry JC, Le Rolle T. Difficult intubation in newborns and infants using an ultra thin fiberoptic bronchoscope. Anaesthesiology 1991;75:436.

[20] Nakayama M, Kataoka N, Usui Y, et al. Techniques of nasotracheal intubation with the fiberoptic bronchoscope. J Emerg Med 1992;10(6):729-34.

[21] Popat M. State of the art: the airway. Anaesthesia 2003;58:1166-71.

[22] Lallo A, Billard V, Bourgain JL. A comparison of propofol and remifentanil target-controlled infusions to facilitate fiberoptic nasotracheal intubation. Anaesth Analg 2009;108(3):852-7.

[23] Johnson C, Roberts JT. Clinical competence in the performance of fiberoptic laryngoscopy and endotracheal intubation: a study of resident instruction. J Clin Anaesth 1989;1(5):344-9.

[24] Reasoner DK, Warner DS, Todd MM, et al. A comparison of anaesthetic techniques for awake intubation in neurosurgical patients. J Neurosurg Anaesthesiol 1995;7(2):94-9.

[25] Gupta B, Kohli S, Farooque K, et al. Topical airway anaesthesia for awake fiberoptic intubation: comparison between airway nerve blocks and nebulized lignocaine by ultrasonic nebulizer. Saudi J Anaesth 2014;8(Suppl 1):S15-9.

[26] Chatrath V, Sharan R, Jain P, et al. The efficacy of combined regional nerve blocks in awake orotracheal fiberoptic intubation. Anaesth Essays Res 2016;10(2):255-61.

[27] Kundra P, Kutralam S, Ravishankar M. Local anaesthesia for awake fibreoptic nasotracheal intubation. Acta Anaesthesiol Scand 2000;44(5):511-6.

[28] Graham DR, Hay JG, Clague J, et al. Comparison of three different methods used to achieve local anaesthesia for fiberoptic bronchoscopy. Chest 1992;102(3):704-7.

[29] Trivedi V, Patil B. Evaluation of airway blocks versus general anaesthesia for diagnostic direct laryngoscopy and biopsy for carcinoma of the larynx. A study of 100 patients. Internet J Anaesthesiol 2009;26:1. 